\title{
Administration of Urban Water Supply, Issues, in Ugep, Yakurr Local Government Area of Cross River State, Nigeria.
}

\author{
Ochiche, Christopher Abua [B.Sc. M.Sc.] Adie, Hilary Idiege [B.Sc. M.Sc.] \\ Department of Geography And Environmental Science University of Calabar, Nigeria. \\ Department of Public Administration, University of Calabar, Nigeria.
}

\begin{abstract}
This study is aimed at assessing urban water supply issues in Ugep urban of Yakurr local government area, Cross River State. The study is anchored firstly on identifying the various sources of water supply, secondly, identifying the various factors militating against urban water supply and thirdly discovering possible mitigation measures which are most suitable for the area under study. The major method for data collection was a fifteen item questionnaire administered to a representative sample size of 160 households, 40 from each of the four political wards in Ugep urban, the sampling techniques used were purposive, stratified and simple random sampling techniques. However, the study showed a weak positive correlation coefficient of 0.33 between distance from water source and water availability. Furthermore the study revealed that the most used source of water supply is the public stand pump/borehole, and that factors such as high cost of water bill, installation cost and poor maintenance culture, lack of skilled man-power and poor funding /exploitation of public funds are responsible for the poor performance of the Cross River State water board in the area. Conclusions were made based on finding and recommendations provided to ensure a broader access to urban water supply in an affordable rate.
\end{abstract}

Key words: Urban, Water supply, Issues, Sources, Management, Ugep

\section{BACKGROUND OF THE STUDY}

"Water is life" this is a universal statement which is traceable to the vital role water plays in the body of all organisms (plants and animal), as well as its role in shaping and structuring the non living components of the ecosystem such as the lithosphere (rocks), atmospheric (air) conditions, as they all interact to balance the biosphere thus making it habitable to living organisms. Water makes the earth unique among planets [1]

Water stands as one of the basic needs of man and without it man can't survive. It is in line with this that many scholars have emphasised that the absence or shortage of water in the human body can result in diverse medical complications and death. They also stressed further on the necessity of water in the human body as follows, water is very vital to the human body as all body cells contains about $80 \%$ water and water contributes about $70 \%$ to body weight and most organs depend on it for effective and efficient functioning [2],[4].

The role of water in the ecosystem has been noted right from ancient time when man began his intellectual consciousness. In 610-546BC Anaximander of Miletus stated that "water is the ultimate stuff as all components both living and non living things contain some reasonable percentage of water". This has been projected in diverse ways even in the field of arts such as visual arts and music; an example of such cases is the famous Nigerian musician Late Fela Kuti who in his song "water no get enemy" projects the unique nature of water as a symbol of peace as it is enemy to no man. Water is use for diverse activities such as drinking, washing, cooking, industrial and construction works, transportation etc. It must be noted at this juncture that despite the positive role water plays in our ecosystem, it can also pose a great deal of threat to the environment when it is not well managed [5]. A good example of such events includes flooding erosion water poisoning due to consumption of polluted or contaminated water, all these events have claimed thousands of human lives and destroyed the environment as a whole.

It is for these reasons that the proper management of water as a resource has received much global concern especially in recent times due to the rapid rate of urbanization and population explosion, in the face of industrialization and technological advancement. The Millennium Development Goals (MDGs) report shows that 782 million people $(11 \%)$ of global population lack access to quality water supply especially in the third world countries Nigeria inclusive Internet [3], thus the bases for this research work which seeks to investigate those issues relating urban water supply in Ugep urban of Yakurr L.G.A of Cross River State, Nigeria. 
Yakurr L.G.A under which the community under study (Ugep) which serves as the council headquarters is undergoing rapid urbanization, which reflects in massive increase in population, landmass expansion and socioeconomic activities. This once primitive farming community has gradually transformed into a large urban settlement inhabited by people from all works of life. This process has been of positive effects in terms of infrastructural development (good road networking, schools, electricity etc) a new urban culture. On the other hand it has brought about some urban related problems such as water scarcity due to increase in demand for the resource for diverse uses such as recreation, domestic, industrial, construction, institutional uses etc. water provision never matched with the rate of urban growth [13].

The provision, management, distribution and utilization of this essential utility in the study area forms the backbone of this research work, due to the changes overtime in water supply sources which in ancient times were predominantly streams and locally dug wells which does not have the capacity meet the demands of the population in present times, thus the need for modern sources of water supply such as manual and electric pumped boreholes and the centrally managed pipe bone water popularly known as "water board" which goes for a monthly subscription fee base on usage per-unit. Despite the provision of these modern sources, there is still a question mark in supply in terms of accessibility, reliability and affordability.

\section{Research Question}

1. What are the existing sources of water supply in the study area?

2. Is there equilibrium between water demand and water supply?

3. What is the tariff system and how affordable is it to the consumer?

4. What are the constraints to efficient water supply in Ugep urban?

5. Are the consumers willing to pay higher bills for improved water supply services?

\section{Aims and Objectives}

1. To assess the various sources of water supply in the study area.

2. To examine the special extent of water supply in the study area

3. To identify the various factors affecting efficient water supply in the study area

4. To make useful recommendations base on identified problems.

\section{Study Hypothesis}

H1: There is a significant relationship between distance from water sources and water availability in Ugep urban.

Ho: There is no significant relationship between distance from water sources and water availability in the study area.

\section{The Study Area}

The study area is limited to Ugep urban in Yakurr L.G.A, central senatorial district of Cross River State. Located geographically between latitude $5^{\circ} 45^{\prime} \mathrm{N}$ and $5^{0} 50^{\prime} \mathrm{N}$, longitude $8^{0} 03^{\prime} \mathrm{E}$ and $8^{0} 08^{\prime} \mathrm{E}$.Ugep urban shares boundaries with Adim(Biase LGA) south, Ediba(Abi LGA)east, Ekori and Idomi(Yakurr LGA) to the north respectively. Ugep became the council headquarter in 1987 following when Yakurr was calved out of the old Obubra LGA. This marked the beginning of inward population migration from its hinterlands in search of better means of livelihood.

The people of Yakurr are peaceful and hospitable. They are custodians of an ancient tradition known as the leboku new yam festival which has in recent times attracted much foreign interest in terms of tourism. The area is blessed with a naturally fertile soil for the cultivation of diverse species of crops such as cassava, rice, yam, vegetable etc. This has placed the area as a major source for agricultural produce. As these farm produce are transported to different parts of the country, though in recent times, due to the high level of urbanization in the area, most of it residents are increasingly becoming involve in non-agricultural occupations. In terms of water, Ugep is blessed with so many seasonal and all year round streams which are mostly located at different farm roads.

\section{LITERATURE REVIEW}

\section{The Rationale for Urban Water Supply}

Water is crucial for human survival, existence and development. The sufficient availability and management of the resource is a determinant factor in the social cultural structure of both the developed and underdeveloped nations of the world. In the developing countries, the provision of portable, drinkable water improves health by reducing water related disease such as diarrhea, cholera, dysentery etc, thus reducing the morbidity and mortality rate which provides an efficient workforce to stimulate economic growth [2]. It is in 
this light that Richard Sule stressed that the demand for safe, adequate, accessible and sufficient water has increased in recent times, especially in the developing nations due to fast rising standard of living and rapid population increase, thus posing a great deal of challenge to city planners [6].

Approaches to urban water supply

Different nations have adopted diverse approaches for managing the available water resources within their geographical boundaries to ensure its sufficient availability for present and future generations. These approaches determine the success of the process as a whole [14],[15]. It must be noted that the best approach to be adopted by any nation must be on factors such as geographical location, climatic factor, rate of population growth, ground water formation, technology and economy. As such the best approach must be service oriented as this will determine the global water supply level [7].In his book the "Environmental Consequences of Rapid Urbanization in Countries of The Developing World" Prof. Sule stressed on the effects of poorly planned urbanization and poor maintenance culture on poor urban water supply [6].

\section{Service Oriented Approach}

The service oriented approach takes into consideration those technical elements and monopolistic public service delivery which had lead to the failure of the public urban water supply sector in many parts of the world(Nigeria inclusive), this serves as a guide to the "do and don't" to the service providers [13]. He went further to outline those imbalances in this approach as follows;

i. Economically inefficiency in terms of cost recovery for equipment installation and maintenance as well as daily pumping and staff welfare. This is due to the fact that the subscription by users is always very poor.

ii. Socially inequitable as residents of poor/slum settlement may not be able to access the scheme due to poor coverage or financial constraints.

iii. Environmentally hazardous in the sense that the approach stresses the hydrological limit of the region in an attempt to meet the demands of the people thus impacting negatively on the environment

Demand Oriented Approach: This approach focuses on providing satisfactory services to the group of consumers who are willing to pay higher bills for improved services. It also creates broader participation by the private sector, NGOs and community based organization (CBOs) in the area of water supply and sanitation [14]. This approach is said to be potentially socio-economically efficient as it encourages competition by service providers in the sector as well as NGOs. Social responsibility also increases as demand orientation requires greater responsiveness to users.

\section{The Developing World Experience}

In line with the united nations "international decade for action water for life (2005-2015), the UN's secretary general Banki-moon published in 2010 "urbanization brings about opportunities for more efficient water resource management and improved access to safe drinking water, at the same time problems are often magnified in cities and are currently out-pacing our ability to device solutions. He outlined these problems as follow;

i. Lack of access to safe drinking water and sanitation.

ii. Increasing water related disasters such as flood and drought. These have brought great harm on man.

Ghana is not left out of these problem, it is noted that the water supply sector is face with issues such as poor water quality, intermittent supply, high water loses and low water pressure [9]. For this reasons the sector has been privatized.

Richard O. Sule outlined some of the factors responsible for poor water supply as follow;

i. Pollution of water bodies through dumping of refuse in water bodies,

ii. Poor management approach by agencies.

iii. Destruction of pipes by members of he public during road maintenance and construction, and in some cases thieves

iv. Poor funding and looting of public funds by public office holders.

v. Poor community awareness and participation

vi. Lack of trained workforce

vii. Poor funding and management

viii. Unwillingness to pay for service by consumers

ix. Low level of private sector participation

$\mathrm{x}$. Absence of coordinated supervision and monitoring

xi. Use of sub-standard equipment [6].

In most developing nations, if source of water has been identified, the quantity not quality is given priority [16]. 16 percent of sub-saharan Africa have access to clean drinking water [17]. 
The role of policy in urban water supply Law is known to be an instrument for social change as it specifies the do and don'ts of any given society as well as punishment for those who contradict these laws. Policy framework has been used the world over to set standards of living and development in the areas of social, economics, technology, health-care, institutions as well as natural resource uses [10]."Water supply policies are an integral part of the global legislative framework, policy documents on this issue are believed to provide an impetus for the development and provision of water for humans, animals, agriculture and industrial uses, this focuses on supply coverage, quality, reliability, and affordability, thus giving members of the society an equal opportunity in terms of access to water supply" [7].It must be noted here that despite the level of global concern in terms of achieving the above goal, urban water supply policy frameworks in the underdeveloped/developing countries are still poorly implemented as some of the agencies responsible for this are only ceremonial monuments or public fund exploitation avenues. Thus, the call for strict policy formulation and implementation in this sector is urgent.

\section{METHOD OF STUDY}

This study adopted the survey research design, which involves sapling of a cross section of the study population in order to arrive at a generalized conclusion. Hitherto, the cross sectional design was much suitable for this study. This is base on the fact that this study is basically a point-in-time study, that is there was no need of going back to re-sample the opinions of the respondents in regards to the study.

Data used for this study were both continuous and discrete data. The continuous data included data on water availability, distance from water sources, data on income and expenditure on water consumption or subscription. On the other hand, the discrete data were data on number of households and size. However the sources for both sets of data were categorized as either primary source or secondary source data. The primary source data comprises of first hand data collected by the researcher on the field. Secondary data was gathered from second-hand information source such as published and unpublished works which are relevant to the study.

The study area (Ugep urban) is said to have a total population of 146,276 [12] as provided by the 2011 National Census.

The sampling techniques adopted for this study were the purposive, stratified and simple random sampling technique. The purposive sampling technique was adopted to purposively choose a study sample size of one hundred and sixty (160) households in Ugep urban for this study.

Also the entire study area was stratified along political wards divisions. Therefore a total of one hundred and sixty (160), fourty (40) households were randomly selected from each ward and questionnaires administered accordingly.

The major instrument use for data collection was a fifteen item questionnaire covering all important issues in urban water supply and utilization in the study area. Thus, a total of 160 questionnaires were issued, 40 household from each of the four political wards and at the end 150 questionnaires were returned in valuable state. Other methods used include personal observation by the researcher, semi-structure interviews with key members of the public and workers at the Ugep water board service station present at the time of the study.

Data collected were analyzed sing the Pearson product moment correlation technique of analysis which is given as follows:

Formular: $\quad \mathrm{r} \quad=\quad \frac{\frac{1}{n} \sum(\mathrm{x}-\mathrm{x})(\mathrm{y}-\mathrm{y})}{(\sigma \mathrm{x})(\sigma \mathrm{y})}$

Where:

$r=\quad$ the correlation coefficient

$\mathrm{x} \quad=$ distance from water source per household (mitres)

$\mathrm{y}=\quad$ water availability per household (litres)

$\sigma \mathrm{x} \quad=$ standard deviation of $\mathrm{x}$

oy $\quad=$ standard deviation of $\mathrm{y}$

$\mathrm{n}=$ number of sampled household

$\Sigma=\quad$ summation sign

Also in testing the significance of the correlation test, the researcher used the "students" t-test formular which is given thus:

$\mathrm{t}=\mathrm{r} \sqrt{\frac{\mathrm{N}-2}{1-\mathrm{r}^{2}}}$

Where:

$\mathrm{t}=$ the T-test

$\mathrm{r}=\quad$ the correlation coefficient

the degree of freedom is calculated as: N-2. 


\section{DATA ANALYSIS AND PRESENTATION}

\section{Hypothesis}

$\mathrm{H}_{0}$ : There is no significant relationship between distance from water sources and water availability.

$\mathrm{H}_{1}$ : There is significant relationship between distance from water sources and water availability.

Table 4.1: $\quad$ Person Product Moment Correlation

\begin{tabular}{|l|l|l|l|l|l|l|l|}
\hline S/N & $\begin{array}{l}\text { Distance } \\
\text { from X }\end{array}$ & $\begin{array}{l}\text { Water } \\
\mathrm{Y}\end{array}$ & $(\mathrm{X}-\mathrm{X})$ & $(\mathrm{Y}-\mathrm{Y})$ & $(\mathrm{X}-\mathrm{X})^{2}$ & $(\mathrm{Y}-\mathrm{Y})^{2}$ & $\begin{array}{l}(\mathrm{X}-\mathrm{X}) \\
\mathrm{Y})\end{array}$ \\
\hline & 12 & 0 & -18 & -30 & 324 & 900 & 540 \\
\hline 2 & 52 & 14 & 23 & -16 & 529 & 256 & -368 \\
\hline 3 & 67 & 63 & 37 & 33 & 1369 & 1089 & 1221 \\
\hline 4 & 10 & 70 & -20 & 40 & 400 & 1600 & -800 \\
\hline 5 & 8 & 3 & -22 & -27 & 484 & 484 & 594 \\
\hline TOTAL & 150 & 150 & & & & & \\
\hline MEAN & 30 & 30 & & & & & \\
\hline
\end{tabular}

Formular $\quad \mathrm{r}=\frac{-\mathrm{b} \pm \sqrt{\mathrm{b}^{2}-4 \mathrm{ac}}}{(\delta \mathrm{X})(\delta \mathrm{Y})}$

$\mathrm{x}=$ Distance from water source in kilometres

$\mathrm{y}=$ Water availability in litres

$\mathrm{x}=30$

$\overline{\mathrm{y}=30}$

$\delta \mathrm{x}=25$

$\delta \mathrm{y}=29$

$\mathrm{r}=0.33$

Using the students T-test with the formular to test significance:

$\mathrm{t}=\mathrm{r} \sqrt{\frac{\mathrm{N}-2}{1-\mathrm{r}^{2}}}$

$\mathrm{H}_{0}$ : The weak positive correlation coefficient obtained occurred by chance.

$\mathrm{H}_{1}$ : The weak positive correlation coefficient did not occurred by chance.

$\mathrm{T}(\mathrm{cal})=0.33$

$\mathrm{D} / \mathrm{F} \quad=3$

$\mathrm{T}(\mathrm{tab})=3.18$

Decision

Since the table value of 3.18 at 0.05 significance level in a two tailed test is greater than the calculated value of 0.61 , the researcher therefore accepted $\mathrm{H}_{0}$ which states that "there is no significant relationship between distance from water source and water availability. However a correlation coefficient 0.33 or 33 percent is a good indicator that distance from water sources account for $33 \%$ influence on water availability. While other factors such as cost of water per liter, population increase, shortage in source supply etc accounts for 67 percent.

Table 4.2: Sources of water

\begin{tabular}{|l|l|l|l|}
\hline S/N & $\begin{array}{l}\text { Sources of } \\
\text { water }\end{array}$ & Frequency & Percentage \\
\hline 1 & Stream/River & 25 & 16.7 \\
\hline 2 & $\begin{array}{l}\text { Public } \\
\text { pump/borehole }\end{array}$ & 100 & 66.6 \\
\hline 3 & Water board & 10 & 6.7 \\
\hline 4 & Private well & 15 & 10 \\
\hline & Total & 150 & 100 \\
\hline
\end{tabular}

Source: Researcher's field work Nov. 2015 
Table 4.3: Sources of reliability

\begin{tabular}{|l|l|l|l|l|}
\hline S/N & $\begin{array}{l}\text { Sources of } \\
\text { water }\end{array}$ & Respondents & Percentage & Scale of reliability \\
\hline 1 & Stream/River & 25 & 16.7 & $3-5$ \\
\hline 2 & $\begin{array}{l}\text { Public } \\
\text { pump/borehole }\end{array}$ & 100 & 66.6 & $8-10$ \\
\hline 3 & Water board & 10 & 6.7 & $3-5$ \\
\hline 4 & Private well & 15 & 10 & $1-3$ \\
\hline & Total & 150 & 100 & \\
\hline
\end{tabular}

Source: Researcher's field work Nov. 2015

Scale: 1-3 (not reliable) 3-5) (reliable), 5-8 (very reliable); 8-10 (satisfactory)

The Table 4.3, shows that $100(66.6 \%)$ respondent households perceive the public pump/borehole source as satisfactorily or perfectly reliable as water can be gotten at any time of the day, while 10 of the respondent perceive the water board (pipe borne water source as just reliable with the scale of (3-5) as factors such electric power supply and technical factors can determine or hinder the supply at different intervals.

Table 4.4: Distance from water Sources

\begin{tabular}{|l|l|l|l|}
\hline S/N & Distance & Frequency & Percentage \\
\hline 1 & $0-5 \mathrm{k}$ & 12 & 8 \\
\hline 2 & $5-10 \mathrm{k}$ & 53 & 35.4 \\
\hline 3 & $10-15 \mathrm{k}$ & 67 & 44.5 \\
\hline 4 & $15-20$ & 10 & 6.7 \\
\hline 5 & $\begin{array}{l}20- \\
\text { above }\end{array}$ & 8 & 5.3 \\
\hline & Total & 150 & 99.9 \\
\hline
\end{tabular}

Source: Researcher's field work Nov. 2015

Table 4.4 shows that $44.5 \%$ (67 households) walk a distance of about 10-15 kilometres from their source of water, 5.3\% (8 households) walk a distance of about 20 kilometres and above to their source of water. It must be noted that most of these residents who walk 20 kilometres and above reside in the newly developed parts of the town where water staid pumps are yet to be provided.

Table 4.5: Household consumption in-litres

\begin{tabular}{|l|l|l|l|}
\hline S/N & Litres & Frequency & percentage \\
\hline 1 & $1-20$ & 0 & 0 \\
\hline 2 & $20-40$ & 14 & 9.3 \\
\hline 3 & $40-60$ & 63 & 42 \\
\hline 4 & $60-80$ & 70 & 46.6 \\
\hline 5 & $\begin{array}{l}80- \\
\text { above }\end{array}$ & 3 & 2 \\
\hline & Total & 150 & 99.9 \\
\hline
\end{tabular}

Source: Researcher's field work Nov. 2015

Table 4.5 shows that 70 household (46.6\%) out of the 150 household (respondents) consume within the range of 60-80 litres of water daily, while 14 respondents (9.\%) consume about 20-40litres per-day. It must be noted here that consumption rate is highly dependent on household size and distance to water source as well as cost of water

Table 4.6: Water sufficiency per household

\begin{tabular}{|l|l|l|l|}
\hline S/N & Sufficiency & Frequency & percentage \\
\hline 1 & Sufficient & 52 & 4.7 \\
\hline 2 & $\begin{array}{l}\text { Just } \\
\text { manageable }\end{array}$ & 63 & 42 \\
\hline 3 & Insufficient & 35 & 23.3 \\
\hline & Total & 150 & 99.9 \\
\hline
\end{tabular}




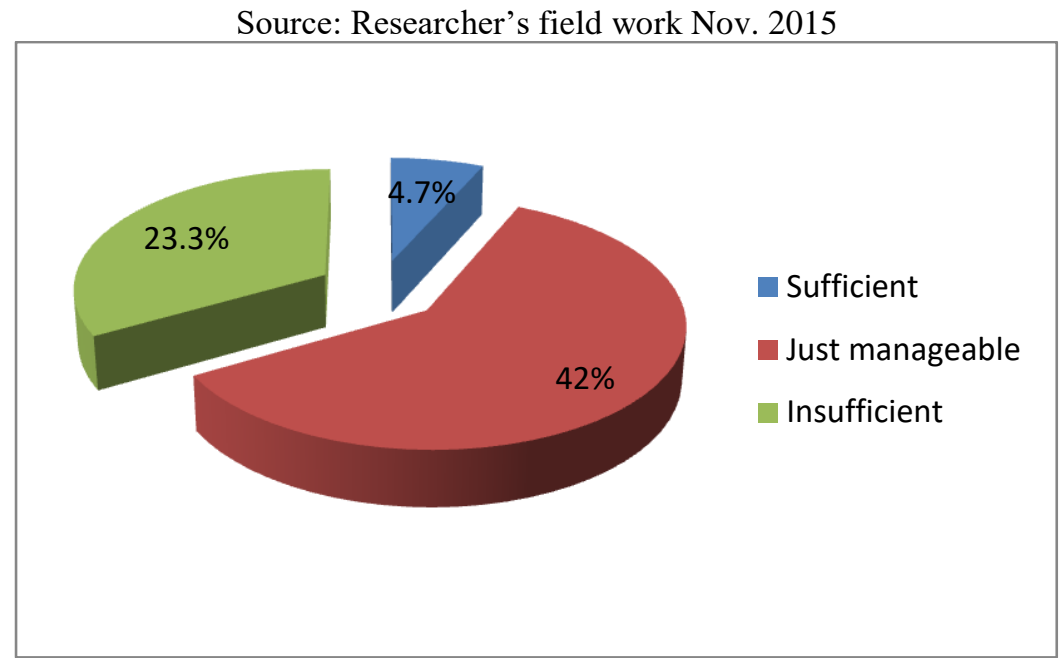

Fig. 4: Water sufficiency per household

According to Table 4.7, 42\% (63 households) have access to just a manageable amount of water, 52 households (34.7\%) have access to sufficient amount of water, while 35 households (23.3\%) receive insufficient quantity of water per-day. This presented in Figure above.

Table 4.7: Connection to CRS water board supply (pipe born water)

\begin{tabular}{|l|l|l|l|}
\hline S/N & Connection & Frequency & Percentage \\
\hline 1 & Yes & 10 & 6.7 \\
\hline 2 & No & 140 & 93.3 \\
\hline & Total & 150 & 99.9 \\
\hline
\end{tabular}

Source: Researcher's field work Nov. 2015

Table 4.8 shows the level of connection of individual residential households to the Cross River State water board service in Ugep urban. A total of 140 respondents (93.3\%) household are not connected to the utility service. On the other hand a total of 10 households $(6.7 \%)$ are connected to the utility.

Table 4.8: Average bill per-month

\begin{tabular}{|c|c|c|c|}
\hline $\mathrm{S} / \mathrm{N}$ & $\begin{array}{l}\text { Estimated } \\
\text { amount }\end{array}$ & Frequency & Percentage \\
\hline 1 & 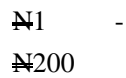 & 0 & 0 \\
\hline 2 & $\begin{array}{l}\$ 200 \\
¥ 400\end{array}$ & 0 & 0 \\
\hline 3 & $\begin{array}{l}\$ 400 \\
¥ 600\end{array}$ & 0 & 0 \\
\hline 4 & $\begin{array}{l}\$ 600 \\
¥ 800\end{array}$ & 3 & 30 \\
\hline 5 & $\begin{array}{l}N 800- \\
\text { above }\end{array}$ & 7 & 70 \\
\hline & Total & 10 & 100 \\
\hline
\end{tabular}

Source: Researcher's field work Nov. 2015

Table 4.8 shows that out of the ten (10) connected households, seven 7 households $(70 \%)$ pay the rate of $\$ 800$ and above for the utility per-month, while 30\% (3 households) pay-month. It must be noted that monthly bill is dependent on monthly consumption per units. 
Table 4.9: Quality of service (CRS water board) in percentage

\begin{tabular}{|l|l|l|l|}
\hline S/N & Scale & Frequency & Percentage \\
\hline 1 & $1-20 \%$ & 0 & 0 \\
\hline 2 & $20-40 \%$ & 6 & 60 \\
\hline 3 & $40-60 \%$ & 4 & 40 \\
\hline 4 & $60-80 \%$ & 0 & 0 \\
\hline 5 & $80-100 \%$ & 0 & 0 \\
\hline & Total & 10 & 100 \\
\hline
\end{tabular}

Source: Researcher's field work Nov. 2015

Table 4.9 shows that $60 \%$ of households using the utility provided by the CRS water board rated the quality of service they receive at $20 \%-40 \%$ efficient. On the other hand $40 \%$ households rated the service at 40 $60 \%$ efficient.

Table 4.10: Reasons for non-connection utility by household

\begin{tabular}{|l|l|l|l|}
\hline S/N & Reasons & Frequency & Percentage \\
\hline 1 & Service not available & 35 & 25 \\
\hline 2 & Service too expensive & 93 & 66.5 \\
\hline 3 & Service not needed & 12 & 8.5 \\
\hline & Total & 140 & 100 \\
\hline
\end{tabular}

Source: Researcher's field work Nov. 2015

According to Table 4.11, 66.6\% (93) non-connected households perceive the utility service monthly changes as too expensive, while $25 \%$ (35) are not connected due to the fact that service is not available to the residential location and $8.5 \%(12)$ households believe the utility service is not needed. It must be noted that most of the households who claim the service is not needed are located close to public stand pumps or bore holds.

Table 4.11: Problem affecting Cross River State water board efficiency

\begin{tabular}{|l|l|l|l|}
\hline S/N & Options & Frequency & Percentage \\
\hline 1 & $\begin{array}{l}\text { Poor } \\
\text { funding }\end{array}$ & 47 & 33.0 \\
\hline 2 & $\begin{array}{l}\text { Staff } \\
\text { negligence }\end{array}$ & 20 & 13.0 \\
\hline 3 & $\begin{array}{l}\text { Non- } \\
\text { payment } \\
\text { of bills }\end{array}$ & 7 & 4.0 \\
\hline 4 & $\begin{array}{l}\text { All of the } \\
\text { above }\end{array}$ & 76 & 50.0 \\
\hline & Total & 140 & 100 \\
\hline
\end{tabular}

Source: Researcher's field work Nov. 2015

The Table 4.11 shows that $76(50 \%)$ of the total sample households (150) receive the major problems facing the Ugep water board operation is due to a combination of poor funding, staff negligence and nonpayment of monthly bills by users, while $7(4.0 \%)$ believe this problems are basically due to non-payment of monthly bills by utility users.

\section{DISCUSSION OF FINDINGS}

As seen in Table 4.3, the major source of water in Ugep urban of Yakurr LGA is the public pumps/bore holes which provide water to $66.6 \%$ of the total population at the time of this study. These public stand pumps are located in strategic areas where they can be easily accessed by the vast population of residents as provided by NGO's, well meaning individuals, government through its programmes. Other sources of water such as private wells, streams water board play complementary roles to individuals who can access them.In terms of 
sufficiency and reliability of supply, those who depend on public pumps perceived this source as the most reliable as water can be accessed at any point in time and at all seasons, making mention of the fact that this stand pump belong to the community and are being controlled by community elders, though a little specific fee is paid to ensure the maintenance of the utility. It must be noted here that the only complain by this stand pump users is in respect of water taste as the water does not taste sweet (according to Clan Head of Lewankum community: Chief Utum Godwin). Users of other sources such as private "we" complained of its seasonal nature as most of these wells dry up during the dry season, likewise the streams. The few households connected to the CRS water board utility in Ugep complained of the unannounced break-in supply which in most cases last for days or weeks without prior-information apology.

\section{Causes of Water Supply Problems}

The causes of water supply problems can be classified into natural factors and man-induced/related factors. Natural factors include climatic factor geologic factor hydrologic factors. These pose a threat which man can do little or nothing to remedy the situation. Rainfall $\mathrm{n}$ tropical Africa is seasonal [13]. The seasonality of rainfall s a basic cause of water scarcity, rain water is allowed to waste during the rainy season and water becomes scarce in the dry season. The inter-tropical divergence (ITD) is a factor that causes rainfall and any unusual delay of its north south movement causes drought [14]. Hence the amount, intensity and duration of precipitation are a major determinant of the hydrological circle (Surface and sub-surface water).

Human factors

Rapid population growth over the years in the study area remains one of the lading factors in water supply problems. With the increase in human activities and diversity in socio-economic activities, those major sources of water which were in the past sufficient for the then small rural population cannot meet up the demands of the present rapidly growing urban population. Other factors such as deforestation for agricultural purpose resulting in evaporation and disruption of hydrological cycle. The substantial rise in the living standard of the increasing population has also accounted for large increase in demand for water, as people now live in modern houses with modern facilities which demands volumes water for domestic cleaning. This is followed by wasteful use of water with the mentality that water as a resource is inexhaustible thus such the attitude manifesting in poor storage methods.

Another major setback in the area of efficient utilization of available water resources in the study area is the dumping of waste into major streams which is a common practice in Ugep urban. This has made most streams in eye-saw and unable to residents who are health conscious. This can been seen in the common practice of washing of cloths and other dirty items directly in water bodies all over the urban area.

\section{Quantity of Water Used Daily Per-Household (See Table 4....)}

According to data gathered through the questionnaire, the quantity of water used daily per-household varies, depending on factors such as household size, financial strength and distance from source of supply. It was discovered that families who reside close to the public stand-pumps and stream use a very high volume of water for their domestic activities likewise residents whose buildings are connected to the CRS water board supply.

Judging the sufficiency of water per-individual was on the World Health Organization (WHO) standard of 61 litres per-person, the bulk of respondents fall below the average daily usage. According to the "table 4.6" only $46.6 \%$ can be said to consume $60-80$ litres and $2 \%$ consuming from 80 litres and above as households of three to five individual. This shows that the larger part of respondents only manage the little quantity they can afford.

\section{Distance Problem}

Distance remains one of the major problems encountered by residents of any urban centre in terms of fetching of water from source to the home. This is mostly prevalent during the dry season when most streams which serve as complementary sources dry up. In line with the "Table 4.5 " about $44.5 \%$ of rests walk a distance of 10-15 kilometers to source for water, $35.4 \%$ cover a distance of 5-10 kilometres, while $6.7 \%$ cover about 15-20 kiometres respectively. This distance is dependent on factors such as old and new residential areas as most newly developed areas are considerably distant from available water sources. Another noticeable point is that location of public stand pumps or boreholes is political as most of this public sources are located in compounds of influential people and such communities such as politicians, chiefs and clan heads etc. This act has widened the gap between the poor and rich as the poor will walk longer distance to water source. Thus spending quality time fetching water which mostly takes many trips.Quality of utility serviceThis aspect has to do with the agency responsible for urban water supply in the study area. This agency is known as CRS water board limited (Ugep supply plant office) located at "Ketabebe community area". 
According to Table 4.8, the level of household connection to the utility is very low with only $6.7 \%$ (10 household out of 150). Factors responsible for the low patronage include high cost of monthly bills, staff negligence, poor funding, poor maintenance culture and cutting of canners (bribery): see Table 4.10 personal observations by the researcher shows that the staffs are not seriously committed to their job as the only come into the distribution office (plant) only when there's a need not as religious worker who work base on official roster, other noticeable actions include the manipulation of the time book. This has resulted in poor service delivery due to avoidable short comings. As such the residents blame government for the intermittent water supply experienced in the area. Although it must be noted that the consumers share some part of the blame in terms of attitude toward payment of monthly bills as they will rather pay bribe to disconnection officers.

\section{CONCLUSION}

Prospects of domestic water supply in Ugep urban concern for the state of water supply in Yakurr L.G.A and Ugep urban in particular has grown over time, as the once common utility has gradually become very scarce in recent times. The climatic condition of the study area provides just enough precipitation during the rainy season which is collected for domestic immediate use, in line with the complain by farmers and residents of the area concerning the shortage in rain fall and prolonged dry season, there is need for new modern methods of collection and preservation of rain water for use during the dry seasons.In terms of public private partnership which has presently aided in alleviating the sufferings of the people of the study area by provision of stand pumps, more can still be done to encourage such initiatives. On the other hand, there is need for adequate funding of the public water supply institutions such as the Cross River Water Board Limited in other to expand its coverage to newly developed settlements in the urban area and also ensure transparency, checks and balancing in its processes for efficient and effective service delivery. With the present administration's strives, we can say that all hope is not lost as the government is said to be committed in infrastructural development not just in Yakurr L.G.A but the state as whole.

\section{RECOMMENDATION}

Water as resources can no longer be taken for granted or consider as a free gift or none exhaustible resources because water is increasingly becoming scare owing to increasing population and demand. The provision of domestic water is a necessary condition for urban development. As such, the following steps must be taken as solutions to the problem which forms the basis for this research work:

i. Administrative Agencies: The problem or responsibility of urban water supply in Nigeria rest on the shoulders of specific government assigned agencies or boards. These organizations are established to ensure that there is a balance water availability demand and utilization (consumption) to promote sustainability especially in urban areas with vast increasing population. Such agencies which play key roles to this effect include the Cross River State Water Board limited as well as the Power Holding Company of Nigeria (PHCN).In respect of the Cross River Water Board, inadequately include storage of staff in diverse department, poor attitude of staff toward their job, poor funding and maintenance culture resulting to inefficiency. As such there is need for adequate funding, staff motivation, training and retraining of staff, employment of competent work force, repair and replacement of equipment in the Yakurr water plan.

ii. Consumer Awareness: The consumer (private and corporate) play a vital role in determining the success level of water supply. Thus, there is need for them to be educated on the importance of the resources and best way to utilize the resources for the continuous availability and sufficiency for present and future generation use. Secondly, the consumers must be enlightened on the need for them to pay their water bill to ensure efficient service delivery.

iii. Public-Private Partnership: The private sector plays a very active role in urban development. Presently, a number of private international organization has placed significant role in providing manual and electric stand pumps in strategic locations all over the local government under study which has being proven to be the most accessible of water to the vast population, though the local people are made to pay a little fee for the day-to-day running and maintenance of this stand pump. More can still be done if more private organization are encourage to participate in this sector to bring water resources closer to the .

iv. Legislature: Law remain a vital instrument for social engineering as a stipulate the do and don't of any society as well as the penalty attached to breaking of such regulation. As such legislative/regulatory frame work must be put in place that such set-back in water supply sector such as vandalization of water supply equipments by hoodlum as well as staff poor attitude to work are checked and punished when necessary.

\section{REFERENCES}


[1] Pickford, John, Water Treatment in Developing Countries, in Faechen R. et al(eds), Water Waste and Health in Hot Climate, (Chichester, John Wiley and Sons, 2007)

[2] Ekpo, G. A., Peri-urban Water and Sanitation Services: Policy, Planning and Method, Springe, P. 300, ISBN 978-90-481-9424-7, 1990.

[3] Http//www.who.int-/docstere/water-sanitation/health/globalassessment/global3.4htm(2000):Global water supply and sanitation assessment report 2000

[4] Ayoade, O. and Oyebande, L., Water Resource in Oguntoyinbo et al (eds), A Geography of Nigeria Development, (Ibadan, Heinemann, 2008).

[5] Olson, E. D., Think before you drink: the failure of the Nation's Drinking Water System to Protect Public Health, Natural Resource Defense Council, New York, 2003.

[6] Richard O. Sule, Urban Physical Development Planning In Nigeria, A Shift In Paradigm (Calabar, 2008)

[7] Banki-moon, International decade action water for life (2005-2015), UN's secretary general Sectorial Report, 2010.

[8] Banki-moon, United Nations Decade International, decade "action water for life 2005-2015" report; accessed October $20^{\text {th }} 2015$.

[9] wikipadia Atom Feed, 2012

[10] [11] White, G. F., Bradley, D. J. and White A. U., Drawers of Water, (Chicago, University of Chicago Press, 2002).

[11] R. Montgomery Mark, et. Al (ed), (2004): Cities Transformed; Demographic Change And its Implication in The Developing World.

[12] Mani Devyani, Investigating a Demand Orientation In Water and Sanitation Delivery, Annual Journal of The United Nations Center for Regional Development, Naguya, Japan, 2000.

[13] Deverill, P., Bibby, S., Wedgwood, A. and Smout, I., Designing Water Supply and Sanitation Projects to meet Demand in Rural and Peri-urban Communities, WEDC Publication, UK, Loughborough, 2002.

[14] Isham, J. and Kahkonan, S., Institutional Determinants of the Impact of Community based Water Services: Evidence from Sri Lanka and India, Economic Development and Cultural Change, Vol. 50 (3), pp. 667-691, 2002.

[15] Awuah, E., Nyarko, K.B., Owusu, P.A., \& Ose-Bonsu, K., Small town water quality, Desalination, vol. 248, 453-459, 2009.

[16] World Health Organization, Meeting the MDG drinking water and sanitation target: the urban and rural challenge of the decade, $2006 . \quad$ Retrieved from http://www.who.int/water_sanitation_health/monitoring/jmpfinal.pdf.

[17] Eze, B and Abua M. (2oo3);Water Resource Management: Ushie Press Calabar.

[18] Gerd, F. and Herman B.: Restoration of water supply in the contest of Town Development. Journal, Applied Geography \& Development. Vol.15, Pp 54-61.

[19] Helweg Otto (2000): Water For A Growing Population, Supply And Ground Water Issues In Developing Countries, International Water Resource Association, Water International, vol. 25, No.1 .

[20] Merla, A., A Commitment to the Global Environment; The Role of G. E. F. and International Waters, A paper presented at the International Conference of Water and Sustainable Development, Paris, 2004.

[21] McDonald, A. T. and David Kay, Water Resources Issues and Strategies (UK, Longman group Ltd, 2008).

[22] Briscoe, M and Ferranti, K, Development in Water Science: Water Resources in Tropical Africa, Elsevier Scientific Pub, Amsterdam, 2005.

[23] Calow, D. W., Water Management in the Developing Countries, Human Institutional Factors, Natural Resource Journal, Vol. 16, October, 2007.

[24] Fotso, J., Ezeh, A.C., Madise, N.J., \& Ciera, J., Progress towards the child mortality millennium development goal in urban sub-Saharan Africa: they dynamics of population growth, immunization, and access to clean water, BMC Public Health, 7, 218, 2007.

[25] Isaac, K. P., A Chemical Method of Sterilizing Water Without Affecting its Potability, Public Health:601-3, 1995.

[26] McDonald, H and David, J., Water Supply and Settlement patterns in Swaziland and Botswana, Ekistic, Vol. 43,(254), 2004.

[27] Davis, J. and Brikke, F., Making your Water Supply Work, International Water and Sanitation Centre, Occasional Paper Series, Hague, Netherlands, No. 29, 1995 